\title{
Evolution of bioethics education in the medical programme: a tale of two medical schools
}

\author{
Olivia Miu Yung $\mathrm{Ngan}^{1}$ (D) Joong Hiong $\mathrm{Sim}^{2}$
}

Accepted: 16 October 2020 / Published online: 270ctober 2020

(C) Springer Nature Switzerland AG 2020

\begin{abstract}
Bioethics Education in the Anglo-European context developed since 1970 and was incorporated into the undergraduate and postgraduate education, residency training, and continuous education. In the Asia-Pacific region, bioethics education is less structured and often dependent on contextual constraints. This paper provides a cross-sectional analysis, describing institutional experiences in developing bioethics curriculum at two medical schools in Malaysia and Hong Kong. The medical programmes of the two institutions are distinctive in terms curriculum framework, teaching approach, and topic selection, and common challenges include implementation of bioethics courses, students' resistance to bioethics, and limited teaching capacity, emerged as they evolve. The reported experiences revealed that there is room for improvement regarding how medical schools integrate bioethics education in regions where curriculum development remains at an early stage. At least, a bioethics education requires both top-down support from the faculty to improve teaching and educational quality, as well as from the bottom-up approach to empower students to raise awareness and concerns toward bioethics, and helps students developing reasoning through challenging issues.
\end{abstract}

Keywords Bioethics · Medical education - Medical school - Curriculum development · Faculty development $\cdot$ Malaysia $\cdot$ Hong Kong

Olivia Miu Yung Ngan and Joong Hiong Sim contributed equally to this work.

Olivia Miu Yung Ngan

oliviangan@cuhk.edu.hk

1 CUHK Centre for Bioethics, Faculty of Medicine, The Chinese University of Hong Kong, Hong Kong SAR, China

2 Medical Education \& Research Development Unit, Faculty of Medicine, University of Malaya, Kuala Lumpur, Malaysia 


\section{Introduction}

Moral conduct in the clinical practice demonstrated through attitudes and behaviours is a transcendental element in medical education. Entering medical school as students and later becoming clinicians involves a transformative process emphasising knowledge competencies, codes of practice compliance, and moral development (Holden et al. 2015). Clinical knowledge acquisition has been the core in the medical education and establishment of virtues values through bioethics training have been underexplored in medical education.

Bioethics in the Anglo-European context has developed since 1970 and has been incorporated into the undergraduate and postgraduate medical curriculum, residency training, and continuous professional education. In the Asia-Pacific region, bioethics education did not gain attention until the 1990s, and teaching deliveries remained inconsistent and less structured depending on contextual factors (Miyasaka et al. 1999). One of the common barriers in the implementation of a curriculum in a resource-constrained context is a lack of teaching capacity (ten Have 2014). Teaching bioethics requires expertise both in ethics and medicine.

Nonetheless, many teachers who are involved in bioethics curriculum in medical programmes were either philosophers, ethicists, or scientists with limited experience in medicine, or clinicians with inadequate formal training in ethics (Ekmekci 2016; Sim et al. 2019). Universities have a limited capacity to provide professional training of ethics and moral philosophy to sustain teaching quality. Another common challenge is limited curriculum time to include ethics in the packed medical teaching timetable (Ravindran 2008).

Successful curriculum development implementation requires continuous and multifaceted consideration. There is a four-stage framework describing the action plan for progressive changes in the curriculum development, specific to bioethics curriculum in medical education over time, in terms of the implementation, content, teaching capacity, and instruction method (Sherer et al. 2017). In Stage 1, there is no bioethics course in the institution. In Stage 2, bioethics is taught from a philosophy course with a limited clinical perspective, emphasising on theories and knowledge acquisition. The capacity in supporting teaching is little and didactic lecture is the primary teaching delivery. In Stage 3 , bioethics is taught as an independent course, covering ethical issues arise from clinical practice, communication skills, and empathy. In addition to didactic teaching, other teaching methods, including small-group discussion and research project, are adopted to encourage intellectual exchange. In Stage 4, the bioethics curriculum is taught by a multidisciplinary faculty team, including physicians, philosophers, and attorneys. The framework is a good indicator, particularly for developing countries, in determining the current status of bioethics education at medical schools.

Bioethics is taught in almost all medical schools in Malaysia (Sim et al. 2019) and Hong Kong (Becker 2005), and the teaching framework and deliveries vary to a great extent depending on the contextual factors. This paper provides a narration describing institutional experiences in developing bioethics curriculum at two medical schools — the University of Malaya and the Chinese University of Hong Kong. 


\section{University of Malaya}

\section{Local setting}

Malaya gained independence from British colonial rule in 1957. In 1963, Malaysia, comprising the Peninsula (West) and Sabah and Sarawak (East) was formed. The country is run based on parliamentary democracy. The legal system incorporates civil law, derived from British elements, and aspects of Syariah laws for Muslims.

Malaysia, with a population of 32.7 million, is a prime example of a plural society. The largest ethnic groups in Malaysia are the Malays (62\%), Chinese (21\%), Indians $(6 \%)$, and others (1\%) (Department of Information 2016). In Sabah and Sarawak, there is a myriad of indigenous ethnic groups with their own unique culture and heritage. Due to the multi-racial characteristic of the population, it also has varieties of culture, religion, social norms and values. All these cultures have influenced each other, creating a genuinely diversified Malaysian culture.

\section{Malaysia Medical Council}

The Malaysian Medical Council (MMC) operates under the Medical Act of 1971 and regulates the registration and practice of medical practitioners (Malaysian Medical Council 2020). Over the years the MMC has undertaken the role of granting recognition to other medical schools in the country and overseas and added the name of these schools to the existing register of recognised medical degrees in the Second Schedule of the Act. It is recommended that the MMC establishes an active functional 'Education Committee' and that the role of MMC in medical education should be clearly and explicitly stated in the Act. Currently, there are 32 Malaysian medical schools, including 11 public and 21 private institutions (Wong \& Kadir 2017).

\section{Medical curriculum at the institution}

The University of Malaya (UM) is the oldest public tertiary institution in Malaysia, providing a five-year undergraduate medical programme - Bachelor of Medicine and Bachelor of Surgery (MBBS). At present, UM adopts a system-based and problembased approach that integrates the teaching around the major body system, covering both basic scientific foundations and clinical reasoning skills development.

\section{Bioethics teaching in the past}

Before the medical curriculum reform took place in 2013, the teaching and assessment focused on the acquisition of medical knowledge and clinical skills, and the humane aspect of medicine was largely neglected. The course content is divided into three main components that run vertically through the course, namely: (i) the Scientific Basis of Medicine, (ii) the Doctor, Patient, Health and Society, and (iii) Personal and Professional Development.

The Scientific Basis of Medicine component includes the study of the normal human body and its function (Anatomy, Biochemistry, Physiology); the body's reaction to injury (Medical Microbiology, Pathology, Parasitology Pharmacology) and practice- 
based clinical medicine (Anaesthesiology, Biomedical Imaging, Emergency Medicine, Internal Medicine, Obstetrics and Gynaecology, Orthopaedic Surgery, Opthalmology, Otorhinolaryngology, Paediatrics, Primary Care Medicine, Psychological Medicine, Social and Preventive Medicine Surgery).

The Doctor, Patient, Health and Society (DPHSs) module includes the study of preventive, promotive, environmental and occupational health in the community; medical statistics, epidemiology, two field projects (Community Residency Program, CRP; Organisation and Management of Health Services, OMHS); Community Family Case Studies, CFCS and family health.

The Personal and Professional Development (PPD) module includes improvement of learning, analytical, critical thinking and communication skills, nursing skills, medical ethics, research methodology and exposure to optional fields of interest via elective programs.

Under the past curriculum, bioethics was appended under Personal, and Professional Development theme and lecture was the primary mode of delivery. There was no formal assessment on the subject. Bioethics was not a popular subject among medical students. This was reflected by poor attendance, in particular, among pre-clinical students. Some faculty members also do not consider bioethics a 'real' topic to be taught. At that time, the development of bioethics education was slow and insignificant.

\section{The current situation: Bioethics curriculum design and content}

Starting from 2013, the Medical Education and Research Development Unit (MERDU) has been actively involved in the curriculum reform and is now responsible for overseeing the bioethics curriculum. The current medical programme comprises of four themes, namely Basic and Clinical Sciences, Patient and Doctor, Population Medicine, and Personal and Professional Development.

Compared with the past curriculum, the most significant change in the revised curriculum is that Personal and Personal Development module has been upgraded to a theme. While only ethics and professionalism were emphasised previously, bioethics, professionalism, humanities, and health law are given emphasis in the revised curriculum. This is to ensure that students not only grow professionally into good doctors but also receive a holistic experience in humanities other than science teaching in the medical curriculum. A unique feature is the 'Language in Medicine' component, which provides an early introduction to the humanities in medicine (Sim et al. 2017). Students learn about icons in medicine, historical events in medicine, death and dying, end-oflife issues, and organ transplantation. (Figure 1).

Today, bioethics is not taught as an independent course or a stand-alone course but as part of an integrated curriculum. Moral theories and related application are oriented vertically and horizontally along with relevant clinical topics. For example, core topics such as informed consent and confidentiality are introduced in Year 1 and revisited throughout the programme (vertical integration). Other contentspecific topics such as ethical issues in human fertility are embedded into relevant learning block such as Endocrine and Reproductive Health Block in Year 2 (horizontal integration) and revisit in later years during clinical postings such as Obstetrics and Gynaecology (vertical integration). 


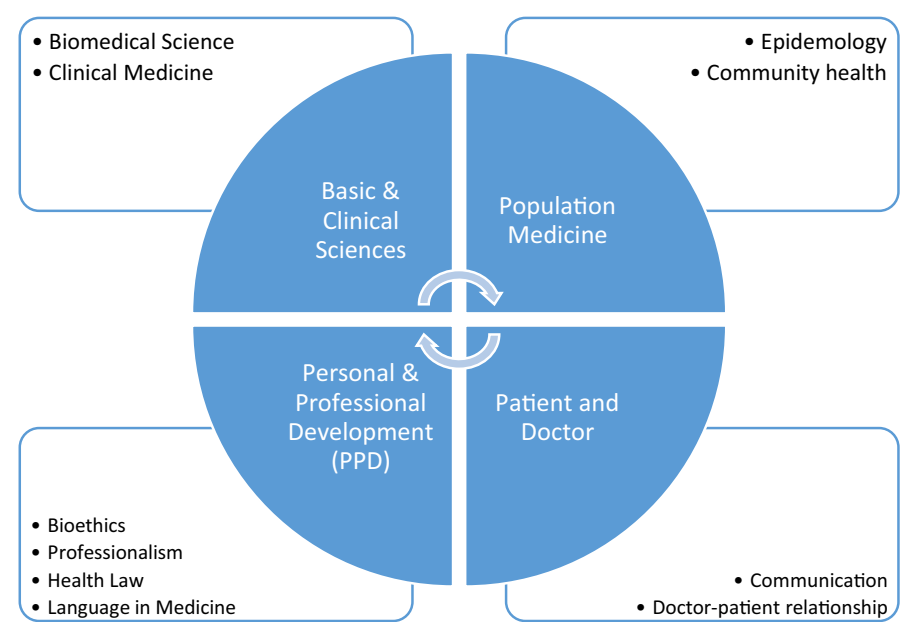

Fig. 1 The four themes in the revised medical curriculum at the University of Malaya

In terms of content, a wide range of topics is being covered. Topics more commonly taught in pre-clinical years include principles of bioethics, history of medicine, origins and philosophy in ethics, and medical humanities. It is believed that these topics need an early introduction to help lay the foundation for bioethics education. Some cases, such as the refusal of treatment, reproductive issues, paediatrics and neonatal issues, are very clinical and could be addressed at a later stage, e.g. during clinical postings. However, certain topics need to be emphasised throughout the medical programme. Some examples are informed consent, patient-doctor relationship, privacy and confidentiality, health law, truth-telling, cultural issues and diversity awareness, religious and spiritual issues, conflicts of interest. These topics aim to prepare medical students for work readiness in the healthcare setting of a plural society like Malaysia.

\section{Faculty and students engagement: Before and after}

Bioethics was not a popular subject among medical students, in particular, among pre-clinical students. Some faculty members also do not consider bioethics a 'real' topic to be taught. Before the medical curriculum reform, the development of bioethics education was slow and insignificant. Nonetheless, since embarking on the change via curriculum transformation in our undergraduate medical programme at the beginning of 2013, our medical school has taken a giant step forward. Murals related to bioethics on the walls of faculty buildings (Figure 2), initiated by faculty members and completed by medical students, is testimony there is increased awareness and acceptance of the importance of bioethics education among faculty members and students. 

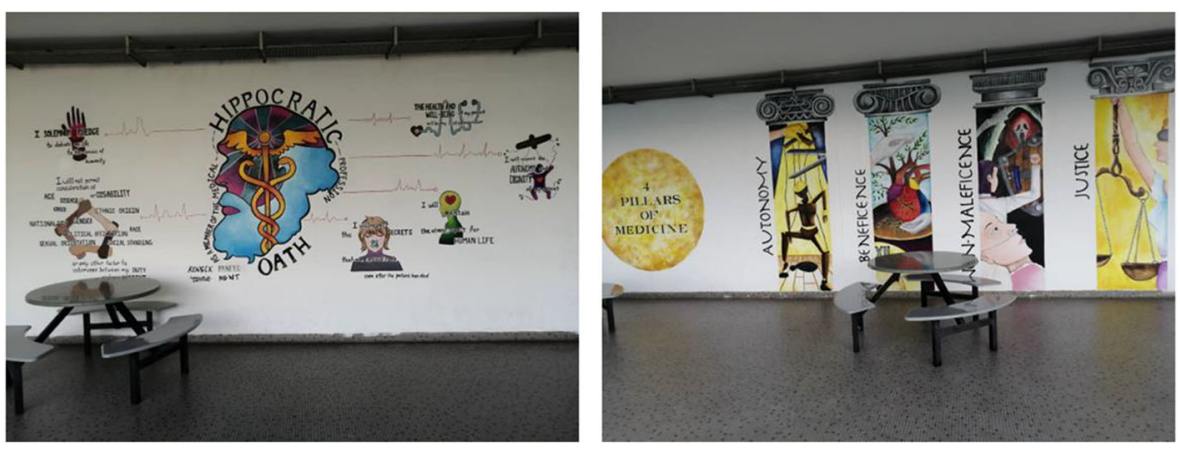

Fig. 2 Mural dedicated to the bioethics teaching and learning at the campus in the University of Malaysia

\section{The Chinese University of Hong Kong}

\section{Local setting}

Hong Kong, now a territory of China, was a former British colony from 1841 to 1997 and the British Common Law system continued after 1997. British influence on the local medical practice and law also endures after the sovereignty handover to China. The current population of Hong Kong is about 7.5 million composed of Chinese (92\%). Among the non-Chinese ethnic groups, the majority are Filipino (4\%), followed by Indonesia (2\%), Caucasian (1\%), and others (3\%) (The Census and Statistics Department, 2017). Compared with Malaysia, Hong Kong is mostly a homogenous society.

\section{The Medical Council of Hong Kong}

The Medical Council of Hong Kong is established under the Medical Registration Ordinance handling the registration, professional conduct and discipline of medical practitioners in Hong Kong. The Council also review the standard and structure of undergraduate medical education and training in the accreditation processes. In 2017, the Council updated the document "Hong Kong Doctors", listing a set of essential attributes and skills in addressing the medical dilemmas and moral difficulties among local medical practitioners (The Medical Council of Hong Kong 2017).

\section{Medical curriculum at the institution}

The Chinese University of Hong Kong (CUHK) is one of the two local universities, providing a six-year undergraduate medical degree programme - Bachelor of Medicine and Bachelor of Surgery $(\mathrm{MBChB})$. It offers comprehensive longitudinal doctoring curriculum to train physicians. At present, CUHK adopts conventional, studentcentred and subject-based curricula offered by the preclinical-clinical division.

\section{Overview of the current medical curriculum}

The first three years of the MBChB curriculum encourage breadth and depth learning, offering pre-clinical studies focusing on interdisciplinary education in the field of 
humanities, social science, natural science. In addition to courses teaching fundamental biomedical courses relevant to medicine (e.g. public health, anatomy, physiology), students are required to courses humanities and language. Before transiting to the clinical year, a six-week bridging course is in place to equip student pathology and clinical anatomy and clinical communications skills.

The latter three years of studies focus on learning advanced biology and clinical medicine subjects, such as anatomical and chemical pathology, anaesthesia and intensive care, diagnostic imaging, clinical microbiology, medicine and surgery. Students receive clinical exposure through a rich mixture of bedside teaching, simulation training, and community or laboratory research opportunities. Courses for communication skills and professionalism are introduced throughout the entire six-year programme. The overarching objective of the medical curriculum is to provide an allrounded training of science and humanities (Figure 3).

\section{Bioethics teaching in the past}

Before the structured bioethics teaching rolled out, ethics was not yet implemented vertically and horizontally that sporadic ethics-related teaching took place on an ad hoc basis in the clinical years only. In 2011, a workshop "Integrated Professionalism Teaching Session" was introduced for final year medical students as part of the induction towards independent clinical practice (Joynt et al. 2018). It is a 5-h session comprises of lectures, small group discussions, and group presentations. The teaching topics broadly include the principles guiding professionalism, medical regulations and government ordinances.

Starting from 2013, the quarterly Clinical Ethics Grand Round was also introduced in parallel in discussions about professional misbehaviours or ethical dilemmas in

\begin{tabular}{|c|c|c|c|c|c|c|c|}
\hline & \multicolumn{3}{|l|}{ Pre-clinical Year } & $\Rightarrow$ & \multicolumn{3}{|l|}{ Clinical Year } \\
\hline & Year 1 & Year 2 & Year 3 & Bridging Course & Year 4 & Year 5 & Year 6 \\
\hline \multirow{8}{*}{ 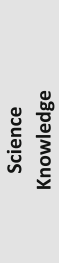 } & Systemic & Human & Advanced Human & Basic & Medicine \& & Obstetrics \& & Medicine \& \\
\hline & Anatomy & Structure & Structure & Pathology & Surgery & Gynaecology & Surgery \\
\hline & Cells \& & Human & Advanced Human & & Anatomical \& & Community \& & Various Clinical \\
\hline & Tissues & Function & Function & Clinical & Chemical & Family & Disciplines \\
\hline & Public Health & Genetics & & Anatomy & Pathology & Medicine & \\
\hline & & & & & Haematology & Paediatrics & \\
\hline & Health Sciences & Molecular & & & & & \\
\hline & & Medicine & & & Microbiology & Psychiatry & \\
\hline
\end{tabular}

\begin{tabular}{|c|c|c|}
\hline 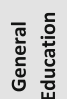 & $\begin{array}{l}\text { Humanity, Social Science, Language, } \\
\text { Physical Education }\end{array}$ & - \\
\hline
\end{tabular}

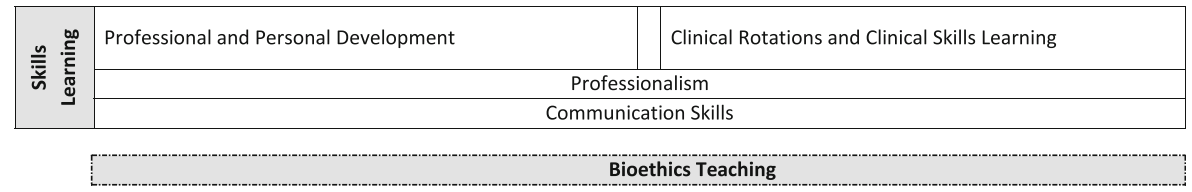

Fig. 3 Coursework during the six-year MBChB Curriculum at the Chinese University of Hong Kong 
healthcare and life science. During the symposium, students and staff members are required to vote using a green-red card that encourages active and interactive participation. In this 2 -h event, students identify key ethical issues that arise in the context of the case, discuss possible conflicting principles, and provide reasonable resolutions based on the four principles approach that underpins much of our teaching of ethics.

With this framework, the teaching of bioethics in the medical schools was the focus in the clinical years only. The acquaintance of ethics knowledge in the pre-clinical year were less emphasised.

\section{The current status: Bioethics curriculum design and content}

Starting from the mid-2015, the new bioethics curriculum is integrated into the curriculum, covering a wide range of ethical issues in biomedical sciences, clinical practice, public health, law, and policy. The teaching goal of bioethics education along three dimensions encompasses acquiring cognitive knowledge and behavioural skills and encouraging positive character development. Besides, teaching modules are designed to raise ethical sensitivity and develop critical thinking skills while encouraging robust communication and interpersonal skills. In the clinical years, students can then link the ethical theory, knowledge, and examples taught in the preceding years for an application to the clinical context.

Table 1 summarises the major themes of the curriculum. The topic-oriented approach in the pre-clinical year entails a teaching goal to (1) observe inter-dependence between medicines and ethics, (2) acquire bioethics knowledge and language, (3) recognise vital ethical issues in medical practice, and (4) apply reasoning skills when present in a dilemma. In the clinical years, students can then link the ethical theory, knowledge, and examples taught in the preceding years for an application to the clinical context.

Table 1 Major Themes of Bioethics Curriculum

\begin{tabular}{|c|c|}
\hline Theme & Description \\
\hline $\begin{array}{l}\text { Historical and Philosophical } \\
\text { foundations }\end{array}$ & $\begin{array}{l}\text { Introduce antecedent circumstances contributing to contemporary } \\
\text { problems, ethical theories, and principles in the analysis }\end{array}$ \\
\hline $\begin{array}{l}\text { Doctor-patient Relationship and } \\
\text { Healthcare Delivery }\end{array}$ & $\begin{array}{l}\text { Address issues arise from healthcare delivery, exploring tensions } \\
\text { between private and public systems of care, as well as potential } \\
\text { conflicts of interest, arise from the organisation and delivery in the } \\
\text { healthcare system }\end{array}$ \\
\hline Emerging Biotechnologies & $\begin{array}{l}\text { Focus on ethical issues at the frontiers of biotechnologies, including } \\
\text { genetic technologies, cloning, and assisted reproductive technologies }\end{array}$ \\
\hline Clinical Ethics & $\begin{array}{l}\text { Examine ethical issues arising at the bedside. Topics include withholding } \\
\text { and withdrawal of life-saving treatment and decision-making at } \\
\text { end-of-life, psychiatry, family medicine, and paediatrics. }\end{array}$ \\
\hline Research Ethics & $\begin{array}{l}\text { Discus ethical questions and conflicts that arise in biomedical research, } \\
\text { protection and safety of human subjects in clinical research, informed } \\
\text { consent, scientific misconduct, and clinical equipoise }\end{array}$ \\
\hline
\end{tabular}




\section{Common challenges encountered in Malaysia and Hong Kong}

The section discusses barriers in the implementation of bioethics teaching from our experience, corroborating with literature.

\section{Student Resistance to Bioethics}

Students' resistance to bioethics learning is a source of challenge. Students, in general, believed that ethics is a 'soft' or 'fluffy' subject that lacks scientific rigour that could be reasoned based on common sense - social and cultural norms - that does not require formal training (Leo \& Eagen 2008). Malaysian and Hong Kong medical students, similarly, also regarded learning of ethics and medical humanities are of lower priority and prefer to spend more time learning clinical knowledge. Ethics in medical education is sometimes regarded as a diversion from the core study of medical knowledge. At worst, ethics may be viewed as a tedious repetition of the obvious with an emphasis on procedural requirements for informed consent, protection of patient confidentiality, etc. Less acknowledged is the unique role of bioethics in the development of core clinical skills such as critical reasoning, familial conflict management, navigation of discourse among professional peers, and understanding healthcare policy. The contemporary bioethics stems moral philosophy applied in research and healthcare contexts and the field has grown ever-present in medical curricula around the globe in an effort to produce doctors capable of navigating complex patient circumstances. However, given that most medical students gravitate towards hard science with its clear and testable answers, the theoretical- and humanities-based roots of bioethics reduce its importance in the eyes of pupils.

Another speculative reason is that students were uncertain about the need for bioethics in pre-clinical years, although they observe the vital role of bioethics for developing the professional identity. Young medical students often neglected the importance of developing moral awareness for a future career during the time of learning 'skills' in early university years. Interestingly, practising physicians observed the importance of bioethics when recognising their identity as primary caregivers as opposed to students (Chan et al. 2011). As young medical student progress to advanced years, they became interested in learning topics related to contemporary ethical issues and moral dilemmas that physicians faced in daily practice (Aldughaither et al. 2012). The discrepant perceived view of bioethics education between young medical students and experienced practising doctors point out the need of a formal orientation about the instrumentality of bioethics training in early medical education years among students whose curricula in high school were predominately focused on mathematics, engineering and natural sciences. In other words, the influence of bioethics on professional identity construction has been largely ignored in reality. It is imperative to connect students with bioethics teaching such that relevance to the future career as a doctor is obvious rather than dismissed.

There are studies in the United States, Netherland, Indonesia, or Nigeria, reported that medical students witnessed unethical decision, unprofessional behaviour, inappropriate conduct by superiors or co-workers in early clerkship (Muhaimin et al. 2019; Okoye \& Nwachukwu 2017; Seiden et al. 2006; Yamey \& Roach 2001). They, however, were uncertain about the resolution in preventing ethical lapses. Importantly, 
implementing ethics training in the clinical years may be late, since students learn by being told what to do by senior doctors with limited opportunity to think and reflect critically (Hren et al. 2011). Bioethics training is not a one-time, but a longitudinal and reflective learning process in the career trajectory shaping a professional identity and cultivate a culture of humanism (Fernandes 2011). It needs to be implemented throughout medical practice years to help reconstruct correct values in medicine in the shifting role from 'layman or students' to 'physician' identity.

\section{Curriculum Design}

When combined with traditional scientific learning, bioethics forms a critical component of comprehensive medical education, which has developed as the new international standard. To achieve parity with global education norms, bioethics teaching must adapt both to evolving learning styles and geographic realities. In the Asia-Pacific context, the Euro-American dominance of teaching materials causes students to dismiss bioethics curricula as impractical.

A lack of local contexts in the curriculum affects the long-term effect of learning. The framework should consider the deliberation of not only locally specific systems and events but also cultural belief systems and philosophical foundation of the society. Modern bioethics which is developed in western philosophies might not adequately provide tools to address ethical complexity in clinical practices of ethical and religious diversity (Chattopadhyay et al. 2013; Fuscaldo et al. 2010). The contested notion of cultural relativism in pluralistic societies as a response to the conventional belief of universality of morals needs to be discussed in bioethics education (Sokol 2016).

The topic of public health is a great example illustrating the need to respect cultural difference from our experience. For instance, in the US context, the use of restrictive measures (i.e. quarantine) in response to infectious disease epidemics was disputable, as it is perceived to violate individual freedom for population good. This contrasts with Hong Kong, where citizens experienced the SARS epidemic in 2003, and using quarantine to monitor individuals for the 'greater good' was found reasonable from the local perspective (Blendon et al. 2006). In Malaysia, the recent examples of COVID-19 challenge the right in a religious gathering while implementing individual movement's restriction (Yezli \& Khan 2020).

Our recent transcultural experience introducing local topics cases has resulted in more lively discussions, with students more willing to express their observations and opinions on topics of bioethical relevance. For example, the discussion of imposing a mandatory influenza vaccination program for healthcare workers is somewhat less challenged in the US (Babcock et al. 2010). Still, it remains unsettled in Malaysia and Hong Kong, which results in a lively debate in the class (Hudu et al. 2016; So et al. 2016). These examples demonstrated that there is no unified approach to ethical problems, and responses are the result of a complex mix of moral and value-related issues (Ngan et al. 2020; Turner 2005). A study also discussed that incorporating cases that are relevant to the local medical systems helps cultivate bioethical responsiveness among the students (Bergstresser et al. 2020). Our learning experience is that placing local contexts as equally as western bioethics enhance the quality of a participatory bioethics teaching in our institutions and it should be done clearly at the design phase of the curriculum. 


\section{Limited Teaching Capacity}

One of the common challenges in the implementation of a bioethics curriculum in a resource-constrained context is a lack of teaching capacity (Sim et al. 2019; ten Have 2014). Teaching bioethics requires expertise both in ethics and medicine, and Universities, nonetheless, have a limited ability to provide professional training of ethics and moral philosophy to sustain teaching quality. In the University of Malaya, there is only a retired O\&G specialist with a law degree, who is well-qualified to teach bioethics. Other faculty members involved in bioethics teaching are mainly clinicians with some exposure to ethical issues in clinical practice but not trained specially in bioethics. In other Malaysian medical schools, bioethics teaching is majorly lead by healthcare professionals or a multidisciplinary team of scientists, lawyers, and ethicists (Sim et al. 2019, Bilgin et al. 2018). In Hong Kong, many teachers who are involved in bioethics curriculum in medical programmes were either philosophers, ethicists, or scientists with limited experience in medicine, or clinicians with some training in bioethics (Rothchild \& Holmquist 2019). To address limited teaching capacity limitation, the faculty development team shall progressively organise workshops to provide training to faulty with little ethics background on areas such as how to integrate bioethics teaching into clinical postings.

Placing local contexts as equally as western bioethics will enhance the quality of a participatory bioethics teaching in Asia, and it should be done clearly at the design phase of the curriculum. To overcome limited teaching resources, the success of the collaborative learning activities depended upon the training of local faculty who were responsible for leading the teaching. Indeed, the concept of "training of trainers (ToT)" has been widely implemented globally in the fields of health education by international institutions (e.g., UN agencies) and major universities in developed countries in resource-limited settings, mostly developing countries (Ewert et al. 2011; World Health Organisation, 2006). UNESCO offers "Ethics Teachers' Training Courses (ETTC)" in developing countries as part of its bioethics professional capacity building programme (ten Have 2019; Langlois 2014). While ToT can be effective to introduce the change in the place of intervention by teaching individuals, providing basic resources and implementing an initiative programme, another level of local resources is necessary to achieve sustainability (Mormina \& Pinder 2018). Thus, the long-term effect of the bioethics curriculum requires the local commitment and leadership as resource-limited academic settings need more collaborative, participatory learning through interaction with teachers and peers in class (Avci 2017).

\section{Conclusion}

This paper described two evolving experiences in implementing bioethics teaching within existing institutional capacity. Both medical schools are unique and very different in terms of the curriculum, and common challenges include curriculum design, students' resistance to bioethics teaching, and limited teaching capacity, were observed as the curriculum evolve. The reported experiences revealed that there is room for improvement regarding how medical schools integrate bioethics education. From a top-down approach, the faculty shall proactively improve teaching and educational 
quality by hosting continuous education sessions. From a bottom-up approach, it is equally crucially to empower students to raise awareness and concerns toward bioethics and helps students developing reasoning through challenging issues.

Authors' contributions JHS conceived the study. OMYN and JHS drafted the manuscript. OMYN made substantial edits on the writing. OMYN and JHS approved the final manuscript.

Data availability Not applicable.

\section{Compliance with ethical standards}

Competing interests All authors declare no conflict of interests.

Code availability Not applicable.

\section{References}

Aldughaither, Saud K., Mohammad A. Almazyiad, Saud A. Alsultan, Abdallah O. Al Masaud, Abdul Rahaman S. Alddakkan, Badar M. Alyahya, Haitham A. Alhassan, Rakan S. Albalawi, Rakan A. Alammar, Majid S. Abaalkhail, and Jamal S. Aljarallah. 2012. Student perspectives on a course on medical ethics in Saudi Arabia. Journal of Taibah University Medical Sciences 7 (2): 113-117.

Avci, Ercan. 2017. Learning from experiences to determine quality in ethics education. International Journal of Ethics Education 2 (1): 3-16.

Babcock, Hilary M., Nancy Gemeinhart, Jones Marilyn, W. Claiborne Dunagan, and Keith F. Woeltje. 2010. Mandatory influenza vaccination of health care workers: Translating policy to practice. Clinical Infectious Diseases 50 (4): 459-464.

Becker, Gerhold K. 2005. Bioethics with Chinese characteristics: The development of bioethics in Hong Kong. In Annals of bioethics: Regional perspectives in bioethics, ed. Mark Cherry and John F. Peppin, 283-306. New York: Routledge Annals of Bioethics.

Bergstresser, Sara M., Kulsoom Ghias, Stuart Lane, Wee-Ming Lau, and Isabel SS Hwang, Olivia MY Ngan, Robert L. Klitzman, and Ho Keung Ng. 2020. What does it mean for a case to be "local"? The importance of local relevance and resonance for bioethics education in the Asia Pacific region. Asian Bioethics Review 12: 173-194.

Bilgin, Ahmet Can, Sevgi Timbil, Cemal Huseyin Guvercin, Sema Ozan, and Semih Semin. 2018. Pre-clinical Students' views on medical ethics education: A focus group study in Turkey. Acta bioethica 24 (1): 105.

Blendon, Robert J., Catherine M. DesRoches, Martin S. Cetron, John M. Benson, Theodore Meinhardt, and William Pollard. 2006. Attitudes toward the use of quarantine in a public health emergency in four countries: The experiences of Hong Kong, Singapore, Taiwan, and the United States are instructive in assessing national responses to disease threats. Health Affairs. https://doi.org/10.1377/hlthaff.25.w15.

Chan, L.K., S.M. Ip Mary, N.G. Patil, and M. Prosser. 2011. Learning needs in a medical curriculum in Hong Kong. Hong Kong Medical Journal 17 (3): 202-207.

Chattopadhyay, Subrata, and Raymond De Vries. 2013. Respect for cultural diversity in bioethics is an ethical imperative. Medicine, Health Care and Philosophy 16 (4): 639-645.

Department of Information, Malaysia Government. 2016. Malaysia Information, Demography of Population. https://www.malaysia.gov.my/portal/content/30114 Accessed 13 Oct 2020.

Ekmekçi, Perihan Elif. 2016. Medical ethics education in Turkey; state of play and challenges. International Online Journal of Education \& Teaching 3 (1): 54.

Ewert, Elena G., Laurel Baldwin-Ragaven, and Leslie London. 2011. Training trainers in health and human rights: Implementing curriculum change in south African health sciences institutions. BMC Medical Education 11 (1): 47.

Fernandes, Ashley K. 2011. Toward a culture of humanism: A proposal for the future of bioethics education in medicine. Medical Science Educator 21 (3): 236-239.

Fuscaldo, G., S. Russell, and C. Delany. 2010. Enhancing cross-cultural understandings of ethical issues in medical education. AJOB Primary Research 1 (1): 28-33. 
Holden, Mark D., Era Buck, John Luk, Frank Ambriz, Eugene V. Boisaubin, Mark A. Clark, Angela P. Mihalic, John Z. Sadler, Kenneth J. Sapire, Jeffrey P. Spike, Alan Vince, and John L. Dalrymple. 2015. Professional identity formation: Creating a longitudinal framework through TIME (transformation in medical education). Academic Medicine 90 (6): 761-767.

The Medical Council of Hong Kong. 2017. Hong Kong Doctors. https://www.mchk.org.hk/english/ publications/files/HKDoctors.pdf. Accessed on 20 May 2020.

Hren, Darko, Matko Marušić, and Ana Marušić. 2011. Regression of moral reasoning during medical education: Combined design study to evaluate the effect of clinical study years. PLoS One. https://doi. org/10.1371/journal.pone.0017406.

Hudu, Shuaibu Abdullahi, Nabil Saad Harmal, Osman Malina, and Zamberi Sekawi. 2016. Influenza vaccination among Malaysian healthcare workers: A survey of coverage and attitudes. The Medical Journal of Malaysia 71 (5): 231-237.

Joynt, Gavin Matthew, Wai-Tat Wong, Lowell Ling, and Anna Lee. 2018. Medical students and professionalism - do the hidden curriculum and current role models fail our future doctors? Medical Teacher 40 (4): 395-399.

Langlois, Adèle. 2014. The UNESCO Bioethics Programme: A review. The New Bioethics 20 (1): 3-11.

Leo, Troy, and Kellene Eagen. 2008. Professionalism education: The medical student response. Perspectives in Biology and Medicine 51 (4): 508-516.

Malaysian Medical Council. 2020. https://mmc.gov.my/ Accessed 13 Oct 2020.

Miyasaka, Michio, Akira Akabayashi, Ichiro Kai, and Gen Ohi. 1999. An international survey of medical ethics curricula in Asia. Journal of Medical Ethics 25 (6): 514-521.

Mormina, Maru, and Sophie Pinder. 2018. A conceptual framework for training of trainers (ToT) interventions in global health. Globalization and Health. https://doi.org/10.1186/s12992-018-0420-3.

Muhaimin, Amalia, Maartje Hoogsteyns, Adi Utarini, and Derk Ludolf Willems. 2019. Ethics education should make room for emotions: A qualitative study of medical ethics teaching in Indonesia and the Netherlands. International Journal of Ethics Education 5: 7-21.

Ngan, Olivia M.Y., Sara M. Bergstresser, Sanip Suhaila, A.T.M. Emdadul Haque, and Helen YL Chan, and Derrick KS Au. 2020. Cultural considerations in forgoing enteral feeding: A comparison between the Hong Kong Chinese, north American, and Malaysian Islamic patients with advanced dementia at the endof-life. Developing World Bioethics 20 (2): 105-114.

Okoye, Onochie, Daniel Nwachukwu, and Ferdinand C. Maduka-Okafor. 2017. Must we remain blind to undergraduate medical ethics education in Africa? A cross-sectional study of Nigerian medical students. BMC Medical Ethics 18 (1): 73.

Ravindran, G.D. 2008. Medical ethics education in India. Indian Journal of Medical Ethics 5 (1): 18-19.

Rothchild, Barbra Bluestone, and Stephanie Holmquist. 2019. Cross-cultural bioethics curriculum development: An example. Medicine and Law 38 (1): 143-152.

Seiden, S.C., C. Galvan, and R. Lamm. 2006. Role of medical students in preventing patient harm and enhancing patient safety. BMJ Quality \& Safety 15 (4): 272-276.

Sherer, Renslow, Hongmei Dong, Yali Cong, Jing Wan, Hua Chen, Yanxia Wang, Zhiying Ma, Brian Cooper, Ivy Jiang, Hannah Roth, and Mark Siegler. 2017. Medical ethics education in China: Lessons from three schools. Education for Health 30 (1): 35.

Sim, Joong Hiong, David S.K. Choon, Vinod Pallath, and Wei-Han Hong. 2017. Humanising medicine: Taking our first step. Medical Education 51 (11): 1186.

Sim, Joong Hiong, Olivia Miu Yung Ngan, and Ho Keung Ng. 2019. Bioethics education in the medical programme among Malaysian medical schools: Where are we now? Journal of Medical Education and Curricular Development. https://doi.org/10.1177/2382120519883887.

So, HC, YH Tam, J Xiao, J Fang, KH Kwok, BJ Cowling, DKM Ip, 2016. Knowledge, attitudes and practices on seasonal influenza vaccination among health care workers in Hong Kong. Paper presented at the ISIRV Options-9 Conference.

Sokol, Daniel. 2016. Teaching medical ethics: Useful or useless? British Medical Journal. https://doi.org/10. 1136/bmj.i6415.

ten Have, Henk AMJ. 2014. Bioethics education in a global perspective: Challenges in global bioethics. Netherlands: Springer.

ten Have, Henk AMJ. 2019. Implementation of ethics education. International Journal of Ethics Education 4 (2): 95-96.

The Census and Statistics Department, the Government of the Hong Kong Special Administrative Region. 2017. Thematic Report: Ethnic Minorities. https://www.had.gov.hk/rru/english/info/info_dem.html.

Turner, Leigh. 2005. From the local to the global: Bioethics and the concept of culture. The Journal of Medicine and Philosophy 30 (3): 305-320. 
World Health Organisation. 2006. WHO training of trainers workshop with minitstry of health on strengthening emergency and essential surgical care at community health centres and primary health centre. https://www.who.int/surgery/activities/ReportIndia_Uttaranchal_Workshop.pdf Accessed 23 May, 2020.

Wong, Rebecca S.Y., and Samiah Yasmin Abdul Kadir. 2017. Medical education in Malaysia: Quality versus quantity. Perspectives on Medical Education 6 (1): 10-11.

Yamey, Gavin, and Jason Roach. 2001. Witnessing unethical conduct: The effects. Western Journal of Medicine 174 (5): 355-356.

Yezli, Saber, and Anas Khan. 2020. COVID-19 social distancing in the Kingdom of Saudi Arabia: Bold measures in the face of political, economic, social and religious challenges. Travel Medicine and Infectious Disease. https://doi.org/10.1016/j.tmaid.2020.101692.

Publisher's note Springer Nature remains neutral with regard to jurisdictional claims in published maps and institutional affiliations. 